\title{
BMJ Open Bone health in bipolar disorder: a study protocol for a case-control study in Australia
}

\author{
Lana J Williams (10 , ${ }^{1,2}$ Amanda L Stuart, ${ }^{1}$ Michael Berk, ${ }^{1,3,4,5}$ \\ Sharon L Brennan-Olsen (1) , Jason M Hodge, ${ }^{1,2,7}$ Stephanie Cowdery, ${ }^{1}$ \\ Vinoomika Chandrasekaran (D) , Julie A Pasco ${ }^{1,2,6}$
}

To cite: Williams LJ, Stuart AL, Berk $\mathrm{M}$, et al. Bone health in bipolar disorder: a study protocol for a case-control study in Australia. BMJ Open 2020;10:e032821. doi:10.1136/ bmjopen-2019-032821

- Prepublication history for this paper is available online. To view these files, please visit the journal online (http://dx.doi. org/10.1136/bmjopen-2019032821).

Received 08 July 2019 Revised 20 December 2019 Accepted 17 January 2020
Check for updates

(C) Author(s) (or their employer(s)) 2020. Re-use permitted under CC BY-NC. No commercial re-use. See rights and permissions. Published by BMJ.

For numbered affiliations see end of article.

Correspondence to

Lana J Williams;

I.williams@deakin.edu.au

\section{ABSTRACT}

Introduction Little is known about the bone health of adults with bipolar disorder, aside from evidence purporting bone deficits among individuals with other mental illnesses, or those taking medications commonly used in bipolar disorder. In this paper, we present the methodology of a case-control study which aims to examine the role of bipolar disorder as a risk factor for bone fragility.

Methods and analysis Men and women with bipolar disorder ( 200 cases) will be recruited and compared with participants with no history of bipolar disorder ( 1500 controls) from the Geelong 0steoporosis Study. Both cases and controls will be drawn from the Barwon Statistical Division, south-eastern Australia. The Structured Clinical Interview for DSM-IV-TR Research Version, Nonpatient edition is the primary diagnostic instrument, and psychiatric symptomatology will be assessed using validated rating scales. Demographic information and detailed lifestyle data and medical history will be collected via comprehensive questionnaires. Participants will undergo dual energy $\mathrm{X}$-ray absorptiometry scans and other clinical measures to determine bone and body composition. Blood samples will be provided after an overnight fast and stored for batch analysis.

Ethics and dissemination Ethics approval has been granted from Barwon Health Research Ethics Committee. Participation in the study is voluntary. The study findings will be disseminated via peer-reviewed publications, conference presentations and reports to the funding body.

\section{INTRODUCTION}

Bipolar disorder, estimated to affect around $2.5 \%$ of the adult population, is a chronic, recurrent condition, characterised by biphasic fluctuations in mood. ${ }^{1}$ Psychiatric comorbidity is common, often complicating diagnoses, management and prognosis, and the risk of early mortality is increased. ${ }^{2}$ Bipolar disorder is also a top 10 cause of years lost due to disability, ${ }^{3}$ with this reflecting the nature of the course and early onset age. As such, the related direct and indirect costs associated with bipolar disorder are notable.
Strengths and limitations of this study

- This case-control study will explore a novel and covert clinical area.

- Both cases and controls will be drawn from the same population.

- A large number of potential confounders will be available for testing in statistical models.

- As with all observational studies, results could be biased by unrecognised confounding and may not be generalisable to other populations.

Aside from psychiatric comorbidities, medical comorbidities are also burdensome. Individuals with bipolar disorder are at increased risk of most disease groups, for example cardiovascular, metabolic, gastrointestinal and pulmonary disease, with such relationships having associated excess mortality. ${ }^{4}$ Research is now emerging to suggest that poor bone health is yet another potential comorbidity. ${ }^{56}$ Both clinically diagnosed unipolar depression and depressive symptoms have been associated with deficits in bone mineral density (BMD) and increases in fracture risk in both men and women across the adult age range, ${ }^{7-10}$ as has schizophrenia, ${ }^{11}$ alcohol use ${ }^{12}$ and eating disorders. $^{13}$ Furthermore, psychotropic agents commonly used in the treatment of bipolar disorder (antidepressants, antipsychotics and anticonvulsants), have each been shown to be independently detrimental to bone. ${ }^{14-16}$

In essence, very little is known about the relationship between bipolar disorder and bone health and the factors involved, apart from what can be implied from other psychiatric disorders. An understanding of the influence of other factors in the relationship of interest is also needed. These include lifestyle factors such as smoking, alcohol, diet and habitual physical activity, socioeconomic status, prescription drug use 
especially psychotropic agents, medical and psychiatric comorbidity and biomarkers of common risk, such as systemic inflammatory and oxidative stress markers. In this paper, we present the methodology of a casecontrol study which aims to examine the role of bipolar disorder as a risk factor for bone fragility. Specifically, we aim to assess:

1. The association between bipolar disorder and parameters of bone health including BMD, bone quality and markers of bone turnover.

2. Whether relationships are explained by specific biological, lifestyle and social factors.

\section{METHOD}

\section{Study design and setting}

This case-control study aims to recruit men and women with bipolar disorder (cases) and use data from peers with no history of bipolar disorder (controls) participating in the Geelong Osteoporosis Study (GOS). Both cases and controls will be drawn from the Barwon Statistical Division (BSD), a geographically well-defined region of south-eastern Australia. The project commenced in 2011 and will be completed in 2020 .

\section{Sampling}

Cases

Men and women with bipolar disorder attending public and/or private healthcare settings within the BSD will be approached to participate. The study will be advertised through the media and all healthcare settings in the region. To be considered for inclusion in this study, participants are required to be aged 20 years or over, have the capacity to consent to participation in the study and to follow its instructions and procedures and meet criteria for a Diagnostic and Statistical Manual of Mental Disorders (DSM-IV-TR) diagnosis of bipolar I, II disorder or not otherwise specified (NOS).

\section{Controls}

Controls will be drawn from a large cohort study. The GOS involves a population-based sample of women and men randomly selected from electoral rolls for the BSD. Originally developed to investigate the epidemiology of osteoporosis, the GOS was expanded to examine psychiatric illness and other common diseases.

During 1994-1997, an age-stratified, random, population-based sample of 1494 women spanning the full adult age range was recruited. In 2001, the male arm of the GOS commenced, comprising a sample of 1540 men aged 20-93years. Male and female control participants with no history of bipolar disorder will be drawn from the most recent follow-up phases of the GOS. Further comprehensive details regarding sampling, recruitment, methodology and outcomes of the GOS are published elsewhere. ${ }^{17}$

\section{Measures}

A listing of psychiatric assessments, clinical measures, biochemical and questionnaire data to be collected is presented in table 1 .

\section{Psychiatric assessments}

The Structured Clinical Interview for DSM-IV-TR Research Version, Non-patient edition (SCID-I/NP) is the primary diagnostic instrument administered to both the cases and controls. This is a validated, semistructured clinical interview for the major axis I psychiatric disorders in the DSM-IV-TR. ${ }^{18}$ Assessments focus on depressive disorders including bipolar disorder (I, II, NOS), major depressive disorder, minor depression, dysthymia, mood disorder due to a general medical condition and substance-induced mood disorder; anxiety disorders including panic disorders, agoraphobia, social phobia, specific phobia, posttraumatic stress disorder, obsessive compulsive disorder, generalised anxiety disorder, anxiety disorder due to a general medical condition, substance-induced anxiety disorder and anxiety disorder NOS; substance use disorders and eating disorders. Information regarding date of onset, frequency, duration and chronicity of episodes will also be collected. The presence of personality disorders including paranoid, schizoid, schizotypal, histrionic, narcissistic, borderline, antisocial, avoidant, dependent and obsessive-compulsive will be assessed using the SCIDII. ${ }^{19}$ All clinical interviews will be conducted by trained personnel with postgraduate qualifications in psychology, under the supervision of a clinically trained psychologist.

Bipolar Depression Rating Scale (BDRS) ${ }^{20}$ and Young Mania Rating Scale (YMRS) ${ }^{21}$ will be used to assess symptoms of depression and mania associated with bipolar disorder. Participants are required to be euthymic at the time of study assessment, denoted by a score of $<16$ on the BDRS and $<14$ on the YMRS.

Mood and anxiety symptomatology will be assessed for all participants using the Hospital Anxiety and Depression rating Scale (HADS), a validated, self-report tool used for assessing clinically significant depression or anxiety in a range of clinical and research settings. ${ }^{22}$ The HADS consists of seven items for depression (HADS-D) and seven items for anxiety (HADS-A), each with a fourpoint ordinal scale to describe symptom severity from 0 to 3 .

\section{Sociodemographics}

Country of birth, ethnicity, education, marital status, housing and employment status and financial support will be self-reported. Occupation type will be categorised according to the Australian and New Zealand Standard Classification of Occupations, Version $1.2,{ }^{23}$ a classification based on skill level and specialisation. Area-based rankings of relative socioeconomic advantage in terms of access to material and social resources will be derived by linking the residential address for each individual to the corresponding Australian Bureau of Statistics (ABS) Census Collection District, and ABS software used to 
Table 1 Psychiatric assessments, clinical measures, biochemical and questionnaire data collected from both case and control participants

\begin{tabular}{|c|c|}
\hline Variable & Instrument \\
\hline \multicolumn{2}{|l|}{ Psychiatric assessments } \\
\hline $\begin{array}{l}\text { Mood, anxiety, substance } \\
\text { and eating disorders }\end{array}$ & $\begin{array}{l}\text { Structured Clinical } \\
\text { Interview for DSM-IV-TR } \\
\text { Research Version, Non- } \\
\text { patient edition }\end{array}$ \\
\hline Personality disorders & $\begin{array}{l}\text { Structured Clinical } \\
\text { Interview for DSM-IV Axis II } \\
\text { personality disorders }\end{array}$ \\
\hline Depression symptoms* & $\begin{array}{l}\text { Bipolar Depression Rating } \\
\text { Scale }\end{array}$ \\
\hline Mania symptoms* & Young Mania Rating Scale \\
\hline Mood and anxiety symptoms & $\begin{array}{l}\text { Hospital Anxiety } \\
\text { Depression Scale }\end{array}$ \\
\hline \multicolumn{2}{|l|}{ Sociodemographics } \\
\hline Country of birth & Self-report \\
\hline Ethnicity & Self-report \\
\hline Education level & Self-report \\
\hline Marital status & Self-report \\
\hline Housing status & Self-report \\
\hline Employment status & Self-report \\
\hline Financial support & Self-report \\
\hline Occupation & $\begin{array}{l}\text { Australian and New } \\
\text { Zealand Standard } \\
\text { Classification of } \\
\text { Occupations, Version } 1.2\end{array}$ \\
\hline Socioeconomic status & $\begin{array}{l}\text { Socio-Economic Indexes } \\
\text { for Areas }\end{array}$ \\
\hline
\end{tabular}

$\begin{array}{ll}\begin{array}{l}\text { Lifestyle } \\ \text { Diet and alcohol consumption }\end{array} & \begin{array}{l}\text { Cancer Council of Victoria } \\ \text { Dietary Questionnaire for } \\ \text { Epidemiological Studies }\end{array} \\ \text { Smoking } & \text { Self-report } \\ \text { Physical activity } & \begin{array}{l}\text { The Baecke Measurement } \\ \text { of Habitual Activity } \\ \text { Physical activity scale for } \\ \text { the elderly }\end{array} \\ \text { Quality of Life } & \text { WHO Quality of Life Scale } \\ & \text { (WHOQOL-BREF) } \\ \text { General Health } & \text { Self-report } \\ \text { Social support } & \text { Multidimensional Scale of } \\ & \text { Perceived Social Support }\end{array}$

Clinical measures

$\begin{array}{ll}\text { Blood pressure } & \begin{array}{l}\text { Digital blood pressure } \\ \text { meter }\end{array} \\ \text { Hand grip strength } & \begin{array}{l}\text { Hand-held dynamometer } \\ \text { (Jamar, Sammons Preston, } \\ \text { Bolingbrook, IL). }\end{array}\end{array}$

\begin{tabular}{ll} 
Medical history & \\
Medical conditions & Self-report \\
\hline
\end{tabular}

Continued

\begin{tabular}{|c|c|}
\hline Variable & Instrument \\
\hline Medication use & Self-report \\
\hline Reproductive history & Self-report \\
\hline Fracture history & Self-report \\
\hline Falls history & Self-report \\
\hline \multicolumn{2}{|l|}{ Pain and somatic symptoms } \\
\hline Pain & $\begin{array}{l}\text { Visual analogue scale } \\
\text { The Foot Disability } \\
\text { Questionnaire } \\
\text { Chronic Back Pain Grade } \\
\text { Questionnaire }\end{array}$ \\
\hline Somatic symptoms & $\begin{array}{l}\text { The Patient Health } \\
\text { Questionnaire-15 }\end{array}$ \\
\hline \multicolumn{2}{|l|}{ Bone and body composition } \\
\hline Weight & Electronic scales \\
\hline Height & Stadiometer \\
\hline $\begin{array}{l}\text { Bone mineral density and } \\
\text { body fat distribution }\end{array}$ & $\begin{array}{l}\text { Dual energy X-ray } \\
\text { absorptiometry scans } \\
\text { (Prodigy; GE Lunar, } \\
\text { Madison, Wisconsin, USA) }\end{array}$ \\
\hline Bone quality & $\begin{array}{l}\text { Quantitative calcaneal } \\
\text { ultrasound (Achilles } \\
\text { InSight; GE Lunar, } \\
\text { Madison, Wisconsin, USA) }\end{array}$ \\
\hline \multicolumn{2}{|l|}{ Biochemistry } \\
\hline Interleukin 6 & ELISAs (R\&D Systems) \\
\hline Total antioxidant capacity & ELISAs (R\&D Systems) \\
\hline C-telopeptide & $\begin{array}{l}\text { ELISAs (USCN Life } \\
\text { Sciences) }\end{array}$ \\
\hline $\begin{array}{l}\text { Amino-terminal propeptide of } \\
\text { type I procollagen (PINP) }\end{array}$ & $\begin{array}{l}\text { ELISAs (USCN Life } \\
\text { Sciences) }\end{array}$ \\
\hline Vitamin $\mathrm{D}_{3}$ & ELISAs (R\&D Systems) \\
\hline
\end{tabular}

${ }^{*}$ Cases only.

derive the Socio-Economic Index For Areas scores, providing a set of summary indexes that indicate relative socio-economic advantage or disadvantage at the small area level. ${ }^{24} 25$

\section{Lifestyle data}

The Cancer Council of Victoria Dietary Questionnaire for Epidemiological Studies (DQES) ${ }^{26}$ will be used to assess consumption of food and alcohol. The DQES notes consumption of 74 foods and six alcoholic beverages over the preceding 12 months using a 10-point frequency scale.

Smoking (current and past patterns of tobacco smoking included manufactured and 'hand-rolled' cigarettes, cigars and pipes) will be gathered by self-report.

Physical activity will be measured using validated questionnaires (Baecke Measurement of Habitual Activity ${ }^{27}$ and the Physical Activity Scale for the elderly), ${ }^{28}$ designed to capture three components of habitual activity, 
including physical activity at work, sport during leisure time and physical activity during leisure time excluding sport.

Quality of life (QOL) will be measured using the WHO QOL Scale (WHOQOL-BREF), ${ }^{29}$ a shortened version of the WHOQOL-100. The WHOQOL-BREF consists of four QOL domains: physical health, psychological health, social relationships and environment.

Self-reported general health will be determined from the question, 'In general, would you say your health is: excellent, very good, good, fair or poor?'.

Perceived social support will be measured using the Multidimensional Scale of Perceived Social Support, ${ }^{30}$ designed to measure support from family, friends and significant others.

\section{Clinical measures}

Blood pressure and pulse rate will be observed using a digital meter with the participant seated. Hand grip strength will be measured using a hand-held dynamometer (Jamar, Sammons Preston, Bolingbrook, IL).

\section{Medical history}

Lifetime history of medical conditions will be obtained by self-report. We will obtain each participant's consent to access their medical records and/or contact their medical practitioners to confirm self-reported conditions. Information regarding immunisation records, reproductive history and falls/fracture history will be ascertained by self-report.

Past and current medication use will be self-reported. Participants will be asked to bring in a list of medications or containers to assist with accurate recording of details.

\section{Pain and somatic symptoms}

Pain will be assessed using the Visual Analogue Scale for pain ${ }^{31}$; a validated, self-report tool used for assessing pain severity during the past week. It includes six separate items that yield a rating for overall pain severity, head pain (headaches), back pain, shoulder pain, interference with daily activities and time in pain while awake. The presence of arm, hand, leg, foot, face, stomach and chest pain will also be documented. The Foot Disability Questionnaire $^{32}$ and the Chronic Back Pain Grade Questionnaire ${ }^{3334}$ will also afford detailed information regarding foot and back pain.

The Patient Health Questionnaire- $15^{35}$ is a validated, self-report somatic symptom subscale derived from the full version of the Patient Health Questionnaire, a selfadministrated version of the Primary Care Evaluation of Mental Disorders diagnostic instrument for psychiatric disorders, which assesses 15 somatic symptoms.

\section{Bone and body composition}

Body weight and height will be measured to the nearest $0.1 \mathrm{~kg}$ and $0.1 \mathrm{~cm}$, respectively.

Dual energy X-ray absorptiometry scans of the spine (posteroanterior projection, L2-4), proximal femur, total body and forearm sites (ultradistal and distal 33\%) will be conducted using a GE-Lunar Prodigy (Madison, Wisconsin, USA) to determine areal BMD (aBMD, g/ $\mathrm{cm}^{2}$ ). Body fat distribution, body fat mass and lean mass will be determined from total body scans.

Bone quality will be determined by quantitative calcaneal ultrasound using an ultrasonometer (GE-Lunar Achilles InSight, Madison, Wisconsin, USA) that provides measures of speed of sound, broadband ultrasound attenuation and stiffness index.

\section{Biochemistry}

A morning blood sample will be collected following an overnight fast and stored at $-80^{\circ} \mathrm{C}$. Batch analyses will be conducted at the end of the recruitment phase. Serum/ plasma will be analysed initially for markers of bone turnover, inflammation and oxidative stress.

\section{Sample size}

The statistical analysis will compare data for cases and controls. Based on a power of $80 \%$, statistical significance at the 0.05 level and previous work ${ }^{36}$ calculations suggest we require 200 cases to detect a difference of at least $7 \%$ in BMD at the hip.

\section{Statistical analyses}

Differences in characteristics between cases and controls will be determined using t-tests, Mann-Whitney and $\chi^{2}$ analyses, where appropriate. The association between bipolar disorder and bone fragility (BMD, bone quality or biomarkers) will be explored using multiple regression techniques. The analyses will be stratified by sex. Age, weight, height, smoking status, activity level, sociodemographic factors, calcium intake, alcohol consumption, vitamin D levels, other psychiatric disorders, biomarkers and medications known to influence bone metabolism positively (hormone therapy, bisphosphonates, lithium) and negatively (corticosteroids, anticonvulsants, antipsychotics and antidepressants) will be tested in the statistical models as potential confounders or effect modifiers.

\section{Ethics and dissemination}

Participation in the study is voluntary and written informed consent will be obtained from all participants. Data are stored on the mainframe computer of Barwon Health in password protected databases that are backed up daily from the file server. Entry of new data is performed daily, enabling the maintenance of a current, up-to-date database. Findings from this study will be disseminated via peer-reviewed publications, conference presentations and reports to the funding body. Additionally, a summary of findings will be provided to participants on the completion of the study.

\section{DISCUSSION}

The relationship between bipolar disorder and bone health remains relatively unexplored, with obvious and major public health implications. This case-control study will address important questions regarding the interface 
of bipolar disorder and bone fragility, capturing information on a range of critical covariates including biomarkers, medication use and lifestyle factors. Furthermore, this study will provide valuable insight into the lifestyle factors associated with bipolar disorder and the medical consequences at a population level. The biomarker component of the study will further allow an understanding of the role of inflammatory and oxidative pathways in comorbid medical disorders such as osteoporosis but also the interaction of these pathways in the disorder itself. The high burden of osteoporosis and fractures and the importance of primary prevention and harm minimisation make an independent investigation essential. This research will enable future researchers, clinicians and patients to better understand adverse events associated with bipolar disorder, and develop and evaluate monitoring strategies surrounding bone health in these individuals.

\section{Author affiliations}

${ }^{1}$ School of Medicine, Deakin University, Geelong, Victoria, Australia

${ }^{2}$ Barwon Health, Geelong, Victoria, Australia

${ }^{3}$ Department of Psychiatry, The University of Melbourne, Parkville, Victoria, Australia ${ }^{4}$ Florey Institute of Neuroscience and Mental Health, Parkville, Victoria, Australia ${ }^{5}$ Orygen, The National Centre of Excellence in Youth Mental Health, Centre for Youth Mental Health, Parkville, Victoria, Australia

${ }^{6}$ Department of Medicine-Western Health, The University of Melbourne, St Albans, Victoria, Australia

${ }^{7}$ Geelong Centre for Emerging Infectious Diseases, Geelong, Victoria, Australia

\section{Twitter Sharon L Brennan-OIsen @Brennan_Olsen}

Acknowledgements LJW is supported by a National Health and Medical Research Council (NHMRC, of Australia) Career Development Fellowship (1064272) and a NHMRC Investigator Grant (1174060), MB is supported by a NHMRC Senior Principal Research Fellowship (1059660 and 1156072), SLB-0 is supported by a NHMRC Career Development Fellowship (1107510) and VC is supported by a Deakin University Postgraduate Research Scholarship.

Contributors Conception and design: LJW, JAP, MB. Development of the methodology: LJW, JAP, SLB-0, MB. Draft and review of the protocol: LJW, ALS, MB, SLB-0, JMH, SC, VC, JAP. All authors read and approved the final version.

Funding This study is supported by a competitive project grant from the National Health and Medical Research Council (NHMRC; 1104438, 2016-19). The Geelong Osteoporosis Study (controls) has also received NHMRC Project Grant funding (251638, 2003-05; 299831, 2004-06; 628582, 2010-13).

Competing interests LJW has received grant/research support from Eli Lilly, Pfizer, The University of Melbourne, Deakin University and the NHMRC. MB has been a speaker for Astra Zeneca, Bristol Myers Squibb, Eli Lilly, GlaxoSmithKline, Janssen Cilag, Lundbeck, Merck, Pfizer, Sanofi Synthelabo, Servier, Solvay and Wyeth, and served as a consultant to Astra Zeneca, Bristol Myers Squibb, Eli Lilly, GlaxoSmithKline, Janssen Cilag, Lundbeck and Servier. SLB-0 has received speaker fees from Amgen Australia and Pfizer Australia, and grant/research support from the NHMRC, University of Melbourne, Deakin University, Arthritis Victoria, Arthritis Australia, Australian Association of Gerontology, and the City of Greater Geelong. JAP has received speaker fees from Amgen, Eli Lilly and Sanofi-Aventis and funding from the Geelong Region Medical Research Foundation, Barwon Health, Perpetual Trustees, The University of Melbourne, Deakin University, ANZ Charitable Trust, the American Society for Bone and Mineral Research, Amgen (Europe) GmBH, the BUPA Foundation, Osteoporosis Australia, Australia and New Zealand Bone and Mineral Society and the NHMRC.

\section{Patient consent for publication Not required.}

Ethics approval Ethics approval has been granted from Barwon Health Research Ethics Committee (reference number 10/89).

Provenance and peer review Not commissioned; externally peer reviewed.

Open access This is an open access article distributed in accordance with the Creative Commons Attribution Non Commercial (CC BY-NC 4.0) license, which permits others to distribute, remix, adapt, build upon this work non-commercially, and license their derivative works on different terms, provided the original work is properly cited, appropriate credit is given, any changes made indicated, and the use is non-commercial. See: http://creativecommons.org/licenses/by-nc/4.0/.

\section{ORCID iDs}

Lana J Williams http://orcid.org/0000-0002-1377-1272

Sharon L Brennan-Olsen http://orcid.org/0000-0003-3269-5401

Vinoomika Chandrasekaran http://orcid.org/0000-0002-3910-3248

\section{REFERENCES}

1 Merikangas KR, Jin R, He J-P, et al. Prevalence and correlates of bipolar spectrum disorder in the world mental health survey initiative. Arch Gen Psychiatry 2011;68:241-51.

2 Vieta E, Berk M, Schulze TG, et al. Bipolar disorders. Nat Rev Dis Primers 2018;4:18008.

3 Vigo D, Thornicroft G, Atun R. Estimating the true global burden of mental illness. Lancet Psychiatry 2016;3:171-8.

4 Crump C, Sundquist K, Winkleby MA, et al. Comorbidities and mortality in bipolar disorder: a Swedish national cohort study. JAMA Psychiatry 2013;70:931-9.

5 Chandrasekaran V, Brennan-Olsen SL, Stuart AL, et al. Association between bipolar spectrum disorder and bone health: a meta-analysis and systematic review protocol. BMJ Open 2017;7:e013981.

6 Chandrasekaran V, Brennan-Olsen SL, Stuart AL, et al. Bipolar disorder and bone health: a systematic review. J Affect Disord 2019;249:262-9.

7 Fernandes BS, Hodge JM, Pasco JA, et al. Effects of depression and serotonergic antidepressants on bone: mechanisms and implications for the treatment of depression. Drugs Aging 2016;33:21-5.

8 Schweiger JU, Schweiger U, Hüppe M, et al. Bone density and depressive disorder: a meta-analysis. Brain Behav 2016;6:e00489.

9 Williams LJ, Bjerkeset O, Langhammer A, et al. The association between depressive and anxiety symptoms and bone mineral density in the general population: the HUNT study. J Affect Disord 2011;131:164-71.

10 Williams LJ, Pasco JA, Jackson $\mathrm{H}$, et al. Depression as a risk factor for fracture in women: a 10 year longitudinal study. J Affect Disord 2016;192:34-40.

11 Tseng P-T, Chen Y-W, Yeh P-Y, et al. Bone mineral density in schizophrenia: an update of current meta-analysis and literature review under guideline of PRISMA. Medicine 2015;94:e1967.

12 Abukhadir SS, Mohamed N, Mohamed N. Pathogenesis of alcoholinduced osteoporosis and its treatment: a review. Curr Drug Targets 2013;14:1601-10.

13 Robinson L, Aldridge V, Clark EM, et al. A systematic review and meta-analysis of the association between eating disorders and bone density. Osteoporos Int 2016;27:1953-66.

14 Schweiger JU, Schweiger U, Hüppe M, et al. The use of antidepressive agents and bone mineral density in women: a metaanalysis. Int J Environ Res Public Health 2018;15:E1373.

15 De Hert M, Detraux J, Stubbs B. Relationship between antipsychotic medication, serum prolactin levels and osteoporosis/osteoporotic fractures in patients with schizophrenia: a critical literature review. Expert Opin Drug Saf 2016;15:809-23.

16 Verrotti A, Coppola G, Parisi P, et al. Bone and calcium metabolism and antiepileptic drugs. Clin Neurol Neurosurg 2010;112:1-10.

17 Pasco JA, Nicholson GC, Kotowicz MA. Cohort profile: Geelong osteoporosis study. Int J Epidemiol 2012;41:1565-75.

18 First MB, Spitzer RL, Miriam G, et al. Structured clinical interview for DSM-IV-TR axis I disorders, research version, non-patient edition. SCID-I/NP) New York: Biometrics Research, New York State Psychiatric Institute, 2002.

19 First M MG, RL. S, et al. Structured clinical interview for DSM-IV axis II personality disorders, (SCID-II). Washington, D.C: American Psychiatric Press, Inc, 1997.

20 Berk M, Malhi GS, Cahill C, et al. The bipolar depression rating scale (BDRS): its development, validation and utility. Bipolar Disord 2007:9:571-9.

21 Young RC, Biggs JT, Ziegler VE, et al. A rating scale for mania: reliability, validity and sensitivity. Br J Psychiatry 1978;133:429-35.

22 Zigmond AS, Snaith RP. The hospital anxiety and depression scale. Acta Psychiatr Scand 1983;67:361-70.

23 Australian Bureau of Statistics. The Australian and New Zealand standard classification of occupations (ANZSCO) version 1.2 (cat. No. 1220.0) 2013.

24 Australian Bureau of Statistics. An introduction to socio-economic indexes for areas (SEIFA) 2006. 
25 Brennan SL, Henry MJ, Nicholson GC, et al. Socioeconomic status and risk factors for obesity and metabolic disorders in a population-based sample of adult females. Prev Med 2009;49:165-71.

26 Giles C, Ireland P. Dietary questionnaire for epidemiological studies. Melbourne: Cancer Council of Victoria, 1996.

27 Baecke JA, Burema J, Frijters JE. A short questionnaire for the measurement of habitual physical activity in epidemiological studies. Am J Clin Nutr 1982;36:936-42.

28 Voorrips LE, Ravelli AC, Dongelmans PC, et al. A physical activity questionnaire for the elderly. Med Sci Sports Exerc 1991;23:974-9.

29 Development of the World Health Organization WHOQOL-BREF quality of life assessment. The WHOQOL Group. Psychol Med 1998;28:551-8.

30 Zimet GD, Dahlem NW, Zimet SG, et al. The multidimensional scale of perceived social support. J Pers Assess 1988;52:30-41.
31 DeLoach LJ, Higgins MS, Caplan AB, et al. The visual analog scale in the immediate postoperative period: intrasubject variability and correlation with a numeric scale. Anesth Analg 1998;86:102-6.

32 Garrow AP, Papageorgiou AC, Silman AJ, et al. Development and validation of a questionnaire to assess disabling foot pain. Pain 2000;85:107-13.

33 Von Korff M, Ormel J, Keefe FJ, et al. Grading the severity of chronic pain. Pain 1992;50:133-49.

34 Smith BH, Penny KI, Purves AM, et al. The chronic pain grade questionnaire: validation and reliability in postal research. Pain 1997;71:141-7.

35 Kroenke K, Spitzer RL, Williams JBW. The PHQ-15: validity of a new measure for evaluating the severity of somatic symptoms. Psychosom Med 2002;64:258-66.

36 Jacka FN, Pasco JA, Henry MJ, et al. Depression and bone mineral density in a community sample of perimenopausal women: Geelong osteoporosis study. Menopause 2005;12:88-91. 